Article

\title{
Environmental Issues As an Indispensable Aspect of Sustainable Leadership
}

\author{
Eun-Jung Woo ${ }^{1}$ and Eungoo Kang ${ }^{2, *}$ \\ 1 Graduate School of Interdisciplinary Program in Environmental Education, Seoul National University, \\ Seoul 08826, Korea; victorywej@snu.ac.kr \\ 2 Business and Technology, DBA, Saint Mary's University of Minnesota, Minneapolis, MN 55404, USA \\ * Correspondence: exkang14@smumn.edu
}

Received: 13 July 2020; Accepted: 24 August 2020; Published: 28 August 2020

check for updates

\begin{abstract}
In an era of environmental crisis, the world is at a perilous moment. The fight between sustainability and economical choice has been a contentious matter and the world is facing environmental uncertainties today. The main purpose of the present study is to prepare an integrated exploration of the development of consciousness in all business categories. This study also focuses on the indispensable roles and impact of top management in merging the commitment and abilities to environmental leadership and thus, adds a contemporary insight into how businesses, economic stakeholders, government authorities, and the general human sphere can mitigate the runaway menace of environmental issues. Finally, the current authors conclude that the environment is the supernatural force that is making life a possibility on the planet. Therefore, every human operation should be regulated by the approaches mentioned in this study and efforts made through the strategic principles and theories of leadership.
\end{abstract}

Keywords: sustainable leadership; environmental sustainability; corporate sustainability

\section{Introduction}

Business development and the emergence of technology have tremendously changed the planet more than ever before. As the sphere of business development and investment tasks, a new tone and calls for sustainable leadership and management have heightened. The environment has equally grown to a critical aspect of any kind of business set-up. From Family Businesses and SME (Small to Medium Enterprise) to multinational incorporations, the factor of the business environment and climate will never be the same again. True to the fact that unprecedented times are with us, businesses are on the run to balance business life and the enormous environmental issue. As the 21st century sets in, the business planet is incessantly approaching an arduous and obscure relationship with forces of nature and the environment altogether. Thus, there is little doubt that environmental issues cause worldwide concern and influence every business industry. For example, many food service companies conduct environmental practices which consist of buying ecofriendly food materials and trying to reduce waste [1]. Implications are soaring, and the environmental issues are bulging every day. Without the question of environmental sustainability, the item of sustainable development will remain unabated and utterly frivolous.

Leadership is central to all organizational objectives, as changes in the dynamic, more competitive business environment compel leaders to stimulate innovation by inspiring vision. Changes that have impacted how corporations approach business include environmental sustainability issues due to the lasting effects of climate change. Ecological sustainability is a complex issue as it means that firms have to invest in newer organizational processes and technologies that disrupt not only the status quo but organizational structures. These disruptions can lead to hostile corporate cultures and resistance to 
change, severely impacting creativity and collaboration in the workplace [2]. Therefore, the role of leadership in mediating change within the organization is critical. The prior study [3] indicated that there would be no development without guidance, especially in the social-cultural and human domains. This research is vital for it demonstrates the role of leadership in meeting the organizational objectives without compromising the environment for future generations. While the part of leadership is critical for environmental sustainability endeavors, various leadership styles and perspectives on command may be more proactive than reactive and lead to positive outcomes for the firm. Therefore, ecological sustainability creates a process of influence within the interaction context. Leadership often involves establishing a shared vision, aligning environmentally valid resources, and generating motivation by inspiring how to meet these goals. Leadership is critical, as leaders can augment workforce engagement through corporate social responsibility and address sustainability [4]. However, attaining engagement objectives requires leaders who can employ hands-on employee development, which augments the development of "innovative solutions to environmental, economic and social problems." [5].

For SMEs, it is increasingly enigmatic and equally a predicament to strike a balance between environmental leadership and well-integrated initiatives and the bigger business goals of economic change and profitability. The traditional culture of lack of information and resistance to government interventionism have rapturously undermined and downgraded their position and responsiveness towards external pressures. In that regard, SMEs' environmental commitment is quite limited and cannot impact from top management. Despite the vast literature on roles and values of environmental leadership, the respective meaning, abilities, and systems underlying the matter have been, unfortunately, underexplored. Away from the SMEs, the larger business enterprises, corporations, and multinationals have been a severe threat to the fight against the biting issues of environmental implications. Today, the big business giants across the globe are known by their insane market exploitations and the eventual profit margins and profitability. In this era, it is purely shameful to see the world becoming forgotten and overshadowed by the strategic profit and economic growth strategies. Sustainable leadership is the way to go if the business planet is to impact the environment positively [6]. A lot of studies have demonstrated that managerial consciousness development has a significant influence on the manager's capacity to conduct change, promote innovation, and mitigate complex issues. For instance, Green production and marketing are environmental commitments that are majorly discretionary. As the business environment becomes cause for concern for the current generation, the cause for change has been highly intricated.

For that reason, the main purpose of the present study is to prepare an integrated exploration of the development of consciousness in all business categories. This study also focuses on the indispensable roles and impact of top management in merging the commitment and abilities to environmental leadership. Specifically, the study narrows down to the post-conventional stages of environmental sustainability, consciousness development, and environmental changes management. The context is of corporate greening and environmental green production and marketing. The next segment of the current study is structured as follows. First, past literature and recent studies on environmental leadership from the considerations of consciousness development theories are discussed. A bigger picture of the role of sustainable leadership in handling environmental issues is also painted in the literature review text. In the literature review, past research shows the relationship between sustainable leadership and the overall improvement of organizations and their responsibilities towards the green economy and environmental protection. The next part of the paper is on the solutions towards ecological issues and the strategic interventions to bolster a green business environment-implications of the green approaches and the future of the global business landscape in consideration of the environmental problems.

\section{Aim of Research}

The research aims at exploring solutions that can augment environmental sustainability leadership. 


\section{Literature Review}

Given the gravity of sustainable leadership in business and corporate management, many studies have been done. From learning scholars, experts in business leadership, government agencies, environmentalists, professors in environmental studies, the aspect of sustainable leadership propelled by environmental issues and consequences have been a pivotal concern. Their relentless efforts have produced some of the best literature and studies as far as environmental issues, business management, and policies are concerned. The following covers the various critical studies attached to sustainable leadership, ecological sensitivity and sustainability, and the role of business leadership in environmental sustainability.

\subsection{Sustainablility}

On a literal ground, sustainability refers to the capacity and thresholds to maintain and protect a particular entity, process, or outcome over a period of time [7]. The prior study [8] connotes the concept of improving and maintaining a healthy ecological, social, and economic system for human development. That study [8] claims that if one of the mentioned realms is eliminated, full dispensation and sense of sustainability are lost. Another prior study [9] defines sustainability as a proper dynamic equilibrium that exists in the platforms of interaction between various population groups and the inherent capacity of its interior and exterior environment. The phenomenon spells the population path to develop its ultimate potential with no gaps for irreversible adversities and negative attribution on the background environment it depends upon. He further expounds on human activities and their ability to satisfy and meet the basic and emerging human demands without exhausting the resources at disposal.

The research group of [10] argued that to transform the global society, the economy, and the environment to a sustainable paradigm is a perplexing challenge, and the task confronts man given the context of the overall carrying capacity of the planet. Such calls have been reiterated by [11] with the integration of innovative approaches regarded for efficiency towards the management of realities and business frontiers. In furtherance in the study of [10] argument, the monetary body posits that the ultimate goal of sustainability, in essence, is to keep appropriate equilibrium and alignment between the economy, society, and the general environment in aspects of the regenerative capacity of the planet's ecosystems for existence and support for life.

Business entities view sustainability as an imperative strategy for long-term success and survival. According to the study of [12], sustainability forges a common ground for strategies for excellent interrelationships between the businesses, authorities, society, and the environment. Enterprises and institutions that enjoy robust programs of sustainability have a lasting mark of positivity and progress to the environment, including the natural indispensables of doing and supporting business. According to the study, a growing number of organizations and companies have been compelled to show verifiable information and evidence of social and environmental impact with a common ground and balance for business profitability and economic significance. For the past couple of decades, there was an exceptional increase in terms of corporate sustainability (CS) and Investors' recognition regarding sustainability as a practical management strategy has grown over the years [13].

\subsection{Theories of Leadership that Cultivate Sustainability and Environmental and Sustainable Leadership}

According to the study of [14], there are a number of leadership theories that can, directly and indirectly, implicate environmental issues and challenges. They include Trait Theory, Participatory Theory, Contingency Theory, Great Man Theory, Transformational Theory, and Transactional Theory. The Great Man Theory is opined as the argument that leaders and men endowed and crafted with heroic potentials are poised to be successful leaders. The moral flaws of the theory are evident, and it calls for minimal efforts towards the bigger society's common good. A more inherent picture is painted by the Traits Theory that speaks vehemently on the distinctive nature of true leaders [14]. To stand 
above all in a congregation, organization, or challenge, the individual with leadership traits shows unrivalled margins of confidence, social consciousness, self-confidence, and personality attributes [15]. The prior study [16] affirmed that characters born with special traits such as intelligence, confidence, determination, and idealism, have a firm inclination towards the top stairs of leadership and Trait theory became unpopulous, and its illogical speculations would be disregarded through behavioral theory.

Behavioral theory is based on the behavior pattern, and it avidly differentiates the classes of leaders and followers. When it comes to environmental issues, the behavioral approach stands at the top position, as discovered by research centers such as the Michigan Center [16]. Job-centered behaviors are regarded as parallel to the paradigms of environmental consciousness and sensitivity. Employee-centered and job-centered leadership is the destination for a lost sense of the environment and consideration of independent dimensions of a quality relationship with the society.

\subsection{Servant Leadership}

Being a timeless conception, servant leadership was coined by Robert Greenleaf and was published in 1970. Servant leadership is found in various religious contexts, but as a philosophy in management, leadership, and society, it transcends any form of religious tradition. The study [17] identified almost a dozen characteristics making the reality of servant leadership. They include empathy, healing, persuasion, listening, foresight, stewardship, community-building, and commitment to growing others. Servant leadership is designed with critical priorities of trust-building, developing people, and achieving results [17]. The fundamental principles needed for servant leadership are empowerment, persuasion, and service first. A servant leader is guided by the spirit of serving others before one's personal needs. Through leadership to higher engagement, stronger relationships, and more, trust is built.

\subsection{Ethical and Authentic Leadership}

For environmental and corporate social responsibility (CSR), ethical and authentic leadership is part of the broader scope of environmental leadership. Ethical leaders are destined for mutual trust, social justice, respect, and are solution-oriented to conflicting issues among various parties [18]. They are made to play non-favorites and fight the cloud of distrust all the time. They are guided and driven by integrity and values. On the other hand, authentic leadership incorporates the theories of ethical leadership, including transformation and overlap of the theory of transformational leadership. Authentic leaders are agents of honesty, compassion, altruism, resilience, and optimism. Linking authentic leadership with environmental issues is the foundation of a sustainable organization and roots of CSR.

\subsection{The Relationship between the Economy, Environment, and the Society}

Regarding the science of development, the phenomenon of sustainability seems to influence and shape the future discourse incessantly. By far, the best choices are the ones that are designed with protocols and systems to meet and support the needs of the community. The ultimate choice should be economically and environmentally viable, environmentally, and socially bearable and socially equitable. This relationship creates the interconnection between the domains and spheres of sustainability that define the relationship between the social, environmental, and economic aspects [19].

From the above, it can be concluded that almost everything planned, designed, or executed on the planet has tangible implications on society, the economy, and, most importantly, the environment. Akin to that, the trio of spheres represents interconnected concepts that should form the fundamentals of human, business, and organizational decisions. Sustainable decisions on resource management build a robust foundation for environmental sustainability and the general relationship between the human race and the rest of the planet. The argument made by concepts mentioned in the three sustainability spheres is the real thing once implemented. The spheres consider the role of the environment in every interaction whatsoever [20]. 


\subsection{Environmental Sustainability in a Literal Ground}

The paradigm of environmental sustainability is all about the stature and value of natural planet and environment and how it remains resilient and progressively productive to keep the support needed by human life. Since time immemorial, the issue of sustainable development and the relationship with the environment has been relevant. However, the relevance and sensitivity of environmental sustainability deepen at the dawn of every new day. The question and challenge of context and the way we use it for human economic gains are becoming a lethal dilemma. Many experts and authors have previously produced remarkable texts and reviews on the domain of environmental sustainability [21].

The prior study [6] related environmental sustainability with the extensive ecosystem integrity and the capacity to external factors to support the landscape of doing and managing business enterprises and inventions. In their study, the duo focused on natural capital requirements to be sustainably tapped and used as reliable sources and inputs of economic production. According to the pair, the planet's systems are captured within limits beyond which the equilibrium might be lost. However, the soaring quest for unbridled growth in business imposes ever-bigger demands on natural resources, straining the limits since technology has become an accelerator for the exponential growth. As recently proven by an extension of [6], no sustainability is achievable without systems for social justice. Environment and the natural boundaries supporting the existence and performance of the business are protected through social justice and law. The metaphor of greening should no longer be the threshold for environmental sustainability but an extensive roadmap for sustaining the environment and social justice to every resource offered by the forces of nature.

The paradigm of environmental sustainability is nothing new at all capacities, according to the study of [22], which states that environmental welfare has been a focal point of concern, and attention directed to the issue has been skyrocketing year-by-year. All stakeholders, business owners, and company proprietors are a life of the issue of strained resources and the impact it imposes on environmental welfare. The international community has been engulfed in tussles of striking a balance between implications of businesses, economic expansion to the environment, and the production performance that comes along with strenuous exploitation of resources. The traditional leadership strategy was designed for keeping the course alive. However, the changing world is no longer a welcoming destination for such leadership realms.

The question of eco-sensitive sustainability is never complete without the input of environmental and strategic policies. At all times, the eco-sensitive leader will focus on positioning the conventional profitability and market goals below the integrated eco-sensitivity goals. The emergence and capture of new theories and information keep the spirit of a rejuvenated eco-sensitive business and organizational life. Such business requires growth patterns run and intricated with life-support environments. Ranging from domestic to regional ecosystems, the sensitivity is always the gear towards sustainable planning and leadership.

\subsection{Corporate Greening and Environmental Leadership}

Sustainable leadership is synonymous with corporate greening. The two phenomena are strong pillars for the success story of any sustainable leader. The research group of [23] denoted corporate greening as the process by which small enterprises and corporate firms demonstrate their commitment and concern on matters environment through the implementation of the best strategies. Corporate greening is an addition of value to the ecosystem. The prior study of [24] focused on Green Corporate Image (GCI) and how it shapes the internal and external organizational operations. Their work emphasized the changing roles of management support and integration of the community in making the GCI. The duo also illuminated the Green Behavioral Intentions as part of the protocols and innovations attached to GCI. The relevance of the GCI should be inherently felt and supported by environmental management, firm performance realms, and the society around.

The study of [25] highlighted the famous "green strategy". He also affirmed that to create a green culture entails behavior reinforcement that individuals are compelled to adopt. Policy formulations 
have supported green considerations. Companies like Ricoh, a Japanese-based corporation, have been singled out for their digital office strategies and solutions that keep its impact as green as possible. The study of [25] also discussed the process and development of the enterprise-level green strategy. A maturity assessment within every area production requires adoption levels of the best practices and advancements that heighten the fundamentals of green awareness. To reach the fundamental thresholds of a greening enterprise capacity and implementation roadmaps to seal threatening gaps and overboard economic aspirations. Besides, gap assessments and process reengineering form a critical component of the transformative initiatives designed towards environmental issues and leadership.

\subsection{Environmental Leadership}

Leadership has been a strong scholarship focus for close to a century. Many have associated leadership with education, business, and geopolitics. However, the concept is a scope far much wider than that. The emerging issues and challenges facing humanity have changed the whole domain for good. Aspects of servant leadership akin to environmental leadership are taking a firm position in the world of today. Environmental leadership can be defined as the strategic art of creating an environment for people to succeed. Greening extends beyond sustainability initiatives and keeps every investment and energy towards conservation and sustainable environmental designs [26] and is also mentioned as the support and practice of environmentally action-oriented movements towards protecting land, fauna, flora, and aquatic systems [27]. Environmental leaders are supposed to give a clear picture of a harmonious relationship between the environment, clean technologies, and all eco-products. The author attests the words of the famous American scholar Hellen Keller in his terms of "Alone we can do little, together we can do so much" [27]. Eco-products are the outcomes of a harmonious relationship according to the arguments raised by Hellen Keller. The below Figure 1 shows the summary of prior studies which were attached to sustainable leadership.

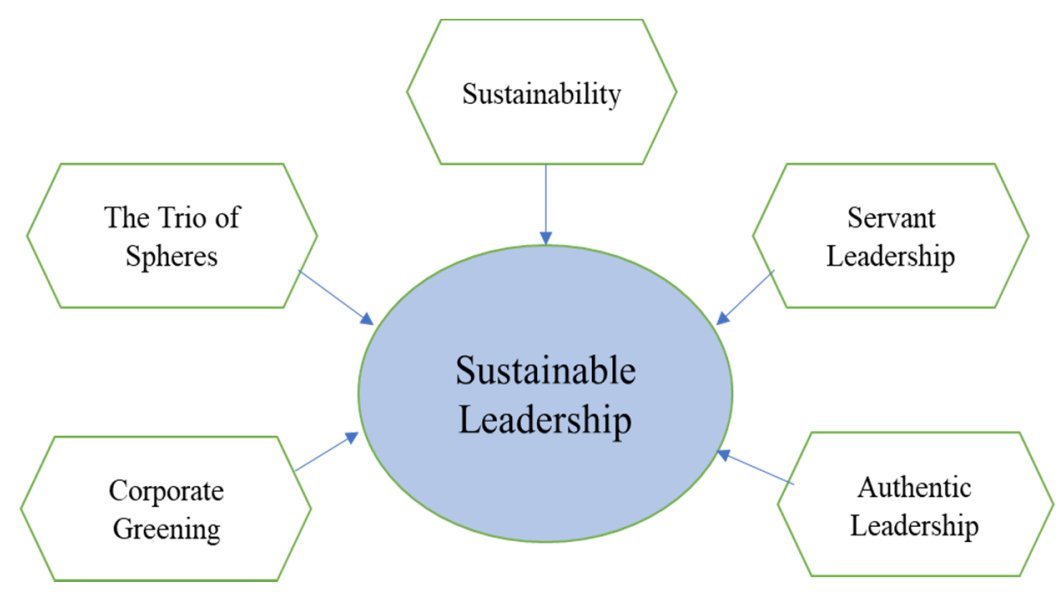

Figure 1. The summary of main prior studies regarding the elements of sustainable leadership.

\subsection{Research Question}

What strategies do leaders in modern organizations use to empower employees towards environmental sustainability?

\section{Methodology}

\subsection{Epistemology Positioning}

Epistemology relates to the nature of knowledge and diverse methods of attaining knowledge [28]. As such, an epistemology asks various questions such as "what are constitutes of valid knowledge, and how can people obtain that knowledge?" To fulfill the objective of this study, the current researchers used an interpretivism paradigm because it inquiries about subjective knowledge. A researcher ought 
to demonstrate the validity and legitimacy of a model used for research [29], particularly for a philosophical grounding of what knowledge is possible [30].

The study integrated an interpretivist paradigm because it sought to create a framework that helps contemporary leaders and organizations merge environmental leadership business strategy. As such, 'interpretivism' was the adequate means to answer the research question because reality is socially constructed and shaped by cultural, historical, social, and political contexts at a given time. Because interpretivism guided this study, the current researchers uses qualitative methodology as it embraces a holistic procedure and action plans with various methods that align with an interpretivist approach.

A review by the study of [31] indicated that an interpretivist rules out natural science methodologies (quantitative) because a qualitative paradigm adopts individuals' knowledge of reality. No singular truth exists when within the interpretivist model because there are diverse meanings to leadership. Thus, assessing these different meanings in environmental leadership would be vital in creating an extensive framework that can guide organizations to adopt guidance that is competitive and still environmentally sustainable. Qualitative methodologies fit with Interpretivism approaches because they are holistic and because qualitative methods seek to understand how and why things happen inductively. A qualitative methodology is crucial because it is unlike methods used in positivist paradigms bound to the rules of science. Becker in seminal research described quantitative methods of analysis as "passive dolls" because they are limiting in that they seek to answer why things happen but are limited to understanding how and why things happen [32].

\subsection{Research Design}

Research designs are an overall approach that a researcher uses to integrate diverse components of a study coherently and logically. The researcher needs to address the research problem effectively, and as such, the research design is a blueprint for the collection, measurement, and, most importantly, data analysis. A research design should thus be appropriate and align with the methodology. A method for social inquiry gains credibility and persuasiveness when these entire domains act in concert with one another, when their interlocking connections are smooth and well planned when the overall presentation is strong, coherent, well-articulated, and thus persuasive. As such, the current researchers collected data from existing research and analyzed data using a content analysis instrument. The research process thus created various codes to generate numerous themes that are solutions for the research problem.

Content analysis used for this research was appropriate because there is tremendous research in the realm of leadership and environmental sustainability. Hence, the current researchers could collect adequate textual data. The prior study affirmed that the reliability of content analysis is dependent on the consistently coding the same way across themes and texts [33]. The safety will be maintained as long the data are interpreted the same way across by anyone analyzing the same data. The research design using data collected from the existing literature is adequate if other researchers can replicate the same results when the same epistemology paradigm, methodology, and design are used. The qualitative primary data collection process is time-consuming and costly. Thus, this research is more appropriate for researchers with limited time and resources as long as validity can be established. For example, methods could be adequate as long as the researcher ensures that there is other evidence available for scrutiny and that the evidence is entirely independent of the study [34].

The new evidence available should reflect the findings and can be in the form of text, open data, or competing theories or interpretations. The research here was qualitative, and thus, subjective meanings guided the context of the study. However, if there is no available means to measure the study, the entire research is prone to invalidity. Therefore, the research design was appropriate because:

- The literature review provided adequate evidence for data collection;

- The data collected were analyzed using an online software tool;

- The analyzed data encompassed the independence of observations among diverse themes; 
- Additional evidence that is independent of this research can validate the data from the content analysis on the solutions found for augmenting environmental sustainability in mediation with leadership.

\subsection{Method}

The advantage of qualitative research is in the ability to avail elaborate textual descriptions on how human beings experience phenomena. Qualitative data incorporates various attitudes, norms, and often cultural factors that people gain subjectively. Unlike quantitative research that only logically predicts, quantifies, and describes statistical data, qualitative research attempts to help people understand issues and, in so doing, describe variation, relationships, and experiences. The researcher used qualitative research because it is more flexible, and since it adapts qualitative methods, it is more straightforward than in quantitative studies. The benefits of conducting qualitative research are that it is meaningful and culturally salient for the participant. Also, research suggests that qualitative research is unanticipated by the researcher and requires the researcher to explore diverse subjects and meanings, which adds a breadth of understanding of the study. Most importantly, the data collected in qualitative research are explanatory and abundant in nature.

\subsubsection{Justification for the Methods Used by the Researcher}

One of the most vital issues in research is to justify why they use objectivist or interpretivist epistemologies. The research group of [35] noted in their study that researchers should use qualitative research when factual data are needed to answer the research questions. Also, the prior study found that qualitative research is preferable when responding to questions about the opinions, attitudes, views, beliefs, and preferences. Regardless of the method, research is adequate if there is a high level of trustworthiness related to an extensive description, explanation, and justification for methods used [36]. For example, the researcher will incorporate a content analysis where the researcher will collect literature review data to assess themes that are most evident in the study. These themes will form the solutions that can be used by business leaders to enhance environmental sustainability and also by other researchers to conduct further research.

Moreover, research can be adequate as long as the researcher can adequately demonstrate its validity [37]. The research, in this case, attempted to provide solutions for business leaders using a qualitative manner. Thus it would be ideal for delivering extensive documentary analysis that can illustrate and support their interpretations.

\subsubsection{Content Analysis}

Content analysis can be used to analyze the written text in many forms, such as articles, letters, and speeches. The key idea of the procedure of this analysis is to maintain the benefits of quantitative content analysis which has been developed in communication science. It can be applied for both manifest and latent text contents. The manifest text refers to the visible, countable textual factors, while hidden content refers to the analysis of data behind the manifest data. When analyzing this research data process, for example, advertisements containing environmental issues may contain fires, melting snow, and extreme temperatures. These aspects are manifest contents, but at a closer analysis, these issues relate to climate change impacts for the next fifty years. The prior study asserted that both types of data taken from a content analysis require interpretation but that elucidations vary in depth and level of abstraction [38]. The current research investigated both latent and manifest themes of leadership and environmental sustainability to find solutions that leaders can use to initiate change in organizations. It is critical to note that the purpose of this study was to present solutions to leadership exploring environmental sustainability. Thus, the aim was to show detailed and predictive results. When presenting descriptive analysis, the researcher addresses the features of a message [39]. On the contrary, predictive results predict the outcomes or effects of the words analyze. For example, in a content analysis research [40], advertising printing impacted on the commodity recalls. 


\subsubsection{Data Collection}

The current researchers collected data from existing literature, including seminal works. The databases were used to collect data mostly from peer-reviewed sources because we needed to augment validity. Additionally, this research utilized a PRISMA (Preferred Reporting Items for Systematic Reviews and Meta-Analyses) statement to identify research within the limits of the study. The PRISMA statement is a checklist developed to summarize evidence on systematic reviews [41]. The research used a PRISMA checklist to ensure that eligible studies were screened, and studies that did not augment this review were excluded. The significance of using PRISMA is that the researcher identifies researches that has limited publication bias and, in so doing, augments the quality of the study [42]. The main measures incorporated into this study were choosing peer-reviewed studies, and thus, the current researchers eliminated conference papers into the analysis. Secondly, the studies included in the research took a positivist or interpretivist dimensions. With these critical criteria, the current researchers could then analyze the text collected using qualitative software.

\subsection{Data Processing with a Content Analysis}

After collecting data using a PRISMA statement as a guide for the analysis, the current researchers used qualitative coding software to examine and interpret it. According to the prior research, qualitative research is vital to study because the value of knowledge includes comprehending credibility, transferability, dependability, and conformability [43]. As such, collected data does not have to encompass a degree of confirmation, refutability, or logical consistency. Instead, as the prior study noted, the research covers wide-based knowledge on a subject that is useful in expanding understanding of an issue [44].

The current researchers coded the collected data using Web QDA (Qualitative Data Analysis) online software. The online content analysis platform is helpful because it helps a researcher to analyze themes in texts and, in a way, enables an ideal method of understanding connection within data categories. For that reason, the researcher identified various groups and then identified emerging themes from the coded data. Qualitative research is inductive, and thus the main objective of the content analysis was to assess the items and emerging topics that would help in providing solutions for this research. However, past researchers discussed that the challenge with content analysis is "differentiating between abstraction level and interpretation degree," which increases the lack of trustworthiness of qualitative data [45]. The researcher limited this risk by showing the logic in how the study categorized themes and categories.

\subsection{Results}

The results of the study are presented in this section, following a systematic process of analysis. Firstly, the current researchers used the existing sustainability and leadership theories to understand the problem. The problem of the research then resulted in creating a research question that the researcher attempted to answer inductively. From this process, we collected data from various chosen journal articles about the potential solutions that can be used for coding development using Web QDA. After receiving data and uploading it on the content analysis platform, we coded the data and created various themes evident as solutions in the data. From these, solutions were found that leaders can use to enhance sustainability within their firm, are we then presented the findings. The following vital themes appeared in the research as the most fundamental solutions for improving sustainability for modern leaders attempting to balance corporate objectives with environmental sustainability:

- Corporate Social Responsibility (CSR);

- the case of the Information Technology Industry;

- $\quad$ fighting the vicious culture of greenwashing in I.T. products and E-waste;

- ultra-regulatory environment;

- $\quad$ organizational sustainability drivers; 
- ethical climate and incentive structure;

- supporting leadership in making of normative professionals;

- drivers of individual-level psychology;

- upscaling the systems of environment communication and decision Information;

- intra-firm communication.

\section{Findings: Solutions to Environmental Issues}

In an era of environmental crisis, the world is at a perilous moment. The fight between sustainability and economical choice has been a contentious matter. Today, the world is facing environmental uncertainties, and the future of seven billion people is incomplete limbo [46]. The tough question of providing for the growing global human population is far from its answers. With the limitations offered by the natural resources and economic potential of technology, giving the seven billion people is a tall order. Many alterations and changes in attitudes, culture, and way of life for business enterprises, domestic and multinational companies, and the governments are a predetermined threshold. Sustainability is the central tool to align the world in a whole new direction in a business and environment common ground. For the entire past decade, sustainability and sustainable leadership have been a buzzword in keeping a balance between the environment and the business space. All sectors of the local and regional economy are parties in the whole matter of sustainability and fighting environmental implications fueled by economic operations and business ventures [21].

As scholars engage in incessant studies and literature development, the challenge is the reality of handling the environmental gaps and intricacies threatening humanity and coexistence with nature. The planet needs a changed tune towards mitigation of the environmental calamities of poor environmental and sustainability leadership. From the very grassroots in business and political leadership, environmental sensitivity is a huge concern, and the challenge is growing at an extraordinary rate. The relationship between the business world and the environment is deteriorating every single day. The burden of solving the situation lies squarely on all of us. The collective responsibility is the lion in the room for many organizations, business enterprises, and the international community altogether. The following is a contemporary insight into how businesses, economic stakeholders, government authorities, and the general human sphere can mitigate the runaway menace of environmental issues. A life to the matter's reality, the following are some of the most imperative interventions and solutions towards sustainable leadership and environmental sensitivity.

\subsection{Corporate Social Resposibility (CSR)}

In the early days, CSR was known as the Social Business and Business Ethics. The World Business Council for Sustainable Development was at the heart of the creation and definition of CSR. The CSR is the incessant commitment of an enterprise entity to act and behave ethically with continuous economic, social, and environmental contributions with an overall intention of changing and impacting society at large. Based on the definition, the business planet has a huge role to play and share responsibility with the rest of the world. In the current era, people consider economic empowerment at the shadow of the adversities posed to the natural world around us [47].

Right from the grassroots, business protocols and regulations should be designed to support CSR. The business culture should be a subject for change if the war and fight against the woes of businesses on the environment succeed [48]. The triple bottom line should be the governing protocol with the ultimate protection on social, economic, and environmental fronts. Despite the business's capacity and size, striking a balance between the paradigms of the triple bottom line should be a mandatory affair and regulation. The world has been missing a moral fiber critical in shaping a sustainable interrelationship between business and the environment. For the past decade, the planet has felt the negative side of a lost foundation and universal approach to Corporate Social Responsibility. The heat is even on the rise and there is no sigh of relief if the demeaning CSR culture persists. 
The time for personal responsibility is far long overdue. The responsibility towards CSR is a sustainable medicine for what the earth is hailing from in this millennium. The political class has a huge role to play in fighting for the future of CSR. Policy regulations and incentives should be designed to phase the new CSR landscape right from the grassroots of the business sphere. Once the rules and policy adjustments are affected, the roadmap to sustainable leadership and environmental sensitivity becomes the order of life [49]. The problems hailing the environment emanates from the irate practices of leadership and corrupt networks that run the economic segments of many countries.

The efforts done by environmental experts, crusaders, and voices against business adversities on the environment are game changers. The future of the economic dimension of the planet is squarely on the responses towards Corporate Sustainable Responsibility. No matter the size of the business or investment, the culture of CSR and giving back in an ultimately good heart, to the society is the path to go. For the entire business planet, CSR is no longer a hype; it has emerged as an invaluable tool for assessing and strategizing on the ways of reduced costs, risk management, internal change actualization, and adoption of the bitter truth of the environmental responsibility from the top leadership [50]. Business interactions and operations are at the heart of the change needed in CSR. CSR should be placed at the top of all policy statements alongside economic goals and financial impact, and the giant industrial players should lead the course. For CSR to be a gamechanger, leaders should always walk the talk. From the political class, business philanthropists, and influential business organizations to the SME space, every leader should walk the talk to honor CSR. As of today, the business world is dominated and taken over by the massive forces of profitability and market dominance.

\subsection{The Case of the Information Technology Industry}

For instance, the technology industry is on a whole new level in terms of profitability and booming expansion. The economic status of the industry is extremely optimistic and on the right path [51]. The economic and consumer impact of technology and the I.T. industry is phenomenal. The world would be at nowhere without the input and interventions offered by I.T. industry solutions. From communication, educations, military, and support sectors to the broader auto and transport industry, I.T. has done wonders. The disastrous concern for the environment plunges the industry leaders and stakeholders in a vast sustainability quagmire. For instance, numerous I.T. vendors worldwide have adopted the best business and product policies of all time [52]. However, the same agility and prowess are far less visible in their own leadership and management of their relationship with the environment. What have the industry players done to demonstrate their respective sustainable picture of leadership and environmental protection?

As the world sails through the space of digital and electronic products, the environment falls a culprit to blotted volumes of waste products and toxic pollutants. The aspect of waste management has plunged most I.T. vendors such as Dell, Apple, Samsung, and Huawei into one of the harshest times of their existence [52]. To show sustainability, the culture of a unilateral economic path should be a thing of the past. Better and serious leadership positions should be taken to fight the agony of I.T. waste, threatening the future of the ecosystem.

\subsection{Fighting the Vicious Culture of Greenwashing in I.T. Products and E-Waste}

Greenwashing is the act of misleading and unscrupulous practices by a company to its consumers on matters of environmental practices. In the space of I.T. products, firms engage in double standards and simultaneously behavioral traits [53]. On one side, they are speaking positive communication about environmental performance, and unfortunately, on the other end, the reality is poor environmental performance and consciousness. The culture that has engulfed the industry is hidden blackmail that equals "poor environmental performances". The infamous "brown firms" are incessantly and taking over. For instance, in Bangladesh and the war-torn nations of the Middle East, the catastrophic menace is killing the face of the natural environment. The legitimate "green firm" culture has been exploited for many of the I.T. vendor' and multinationals' gains. As at the moment, the "brown firms" should 
be compelled by the necessary business and economic sanctions to realign them to the protocols of "green firms".

Studies have revealed that the most vocal firms structured in extreme degrees of positive communication about greening practices are the biggest failures in the environmental leadership and protection of limited natural resources. They are made to blackmail the reality and push the rest of the world and environment to the crisis land of no redemption. The silent firms which are acting in environmental goodwill are known as the "silent green firms". Silent green firms are unique entities in the business environment [53]. They intend to maximize the business and process production with a singled eye on the life of competitions and regulatory organizations. Through inherent policy regulations, organizations in the I.T. industry should transition to greening programs.

Vocal green firms and silent green firms are suitable options for a company in terms of environmental topology. The drivers of greenwashing are becomingly critical. Most firm environmental performance is void of honesty, integrity, and ultimate truth on the real issues facing the environment. Brown firms are the biggest consumers of the drivers of greenwashing. The desire to manipulate the outside world is rife, and they always "communicate positively about their policies and performance on the environment. The intrigues and unfathomable forces of institutional and regulatory bodies should be fought, and countered intensively" [54]. To mitigate the adversities caused by brown companies, effective intra-enterprise communication, ethical climate sensitivity, legitimate incentive structure, and organizational inertia should be modified in utter good faith to allow external regulations to take shape in the war against environmental pollution, degradation, and overall change in the climate.

\subsection{Ultra-Regulatory Environment}

For many years, greenwashing has been limited in the United States. The enforcement of monitoring and regulatory has been hit endless blockades of uncertainty and perspective from affected, affiliate, and peer companies. The Federal Trade Commission (FTC) Act should be tentatively amended. The agency's powers should be heightened beyond federal watch on product and service advertisements that only fall in Section 5 [52]. The FTC should scale up the punishments before violators of the ultra-regulatory environment. As companies grow their financial muscles, the law should be adjusted to support tougher subtle enforcement laws with the FTC Act. The minimum fine of $\$ 10,000$ should be increased to over $\$ 100,000$ for business enterprises, and companies found guilty with an intent to mislead, defraud, or violate environmental sustainability regulations [52]. The complexities that have emerged during the mitigation and hearing of cases unsubstantiated claims supporting the false environmental cases should be condemned at all costs. Through the tightened consequences, the FTC should acquiesce all organizations violating the "all-natural" and "biodegradable" clarities.

For multinationals with their roots beyond the American borders, the FTC Act should be also applicable. However, on that note, they should integrate with the host countries international equivalents such as the Australian Competition and Consumer Commission (ACCC) and the Canadian Standards Association. Misleading advertisements should be eliminated through tougher product seizure, huge fine margins, and even imprisonments. The U.S. government should amend the current corporate disclosure clauses to ensure enhanced environmental practices [55]. Mandatory disclosure of environmental leadership and practices supported by third-party auditing services will ensure that brown firms do not go unpunished with greenwashing.

\subsection{Organizational Sustainability Drivers}

While the external driver realm establishes an environment to incentivize firms towards greenwash, the negative strategies and interventions are never done in a vacuum. Corrupted and unscrupulous organizational drivers form the foundation of the greenwashing strategy. Some of the critical firm-level drivers to adopt a change in sustainable leadership and environment consciousness include intra-firm communication, firm characteristics, ethical climate and incentive structures, and organizational inertia. 
The mentioned drivers should dictate and align the company's reaction and adherence to external forces and drivers fighting greenwashing improprieties [53].

\subsection{Intra-Firm Communication}

Effective intra-firm communication is a powerful tool in the fight against greenwashing. Internal exchanges and the sharing of information with the boundaries of an organization are usually sticky to achieve [53]. Suboptimal domestic transfers of information will help in the explanation of inadvertent greenwashing that is perfected by most "brown enterprises". The data from the technical team and product design specialists should be reliably correct and of utmost integrity for the consumer good and the life after its consumption and the environment around [56]. Connection systems between each department should be channels of intelligence and appropriate management and use of product and service specifications. For electronics and other digital products, the less active components of intra-firm communication should restructure and given a whole new picture and connotation.

Internal subunits fighting is a common trend in many organizations and I.T. ventures as well. Direct relationship platforms are highly needed to build a rigorous and extensive communication and information sharing to avoid greenwashing products at the expense of the natural world around the consumer networks. As part of the wider sustainable leadership, knowledge dissemination, and frequent interaction segments between R \& D (Research and Development), other functions, and top management should be the culture and order of life within the product and service lifecycle corridors.

\subsection{Ethical Climate and Incentive Structure}

A firm's ethical behavior and culture are notably shown through ethical climate and incentive structures of sustainability weights. Unethical behavior is the practice that causes or propagates harmful effects on others, and they may be morally unacceptable or illegal in the larger social sphere. The organizational ethical climate is made up of members and stakeholders' common perceptions and ideologies that specific ethical reasoning or practices are indispensables of decision making. The climate under ethical paradigms should be written on a trio of moral judgment [57]. These are egoistic climate, benevolent climate, and principled climate theories. The dominance of egoistic ethics should be plummeted and significantly replaced using benevolent or principled theories. Despite the audacity, intractability, and conundrum of the egoistic climate theory, explicit industry standards should be formulated to fight the resulting culture and uncertainties. Leaders should rebuild their trust in the environment and deliver the best in the implementation of ethical codes.

Incentive structures are an imposition to reward and uplift managers and leadership systems for attaining financial goals. However, the tricks used by the brown, firm category should not be featured if the environmental impact of the business planet is to be sustainable. Excellent performers in CSR policies and strategies should be given the top priority in the benefits of incentive structures [58]. Arbitrary marketing and P.R. quotas should be intelligently programmed to shade a legit and socially responsible image of the company and its product development. Greening should not be a hiding zone for unfortunate business marketing and P.R. quotas and strategies. The incentive policy should be designed to validate the truth about their products to protect their after-use implications.

\subsection{Supporting Leadership in the Making of Normative Professionals}

The paradigm of normative professionalism insists on the significance of the personal side of a professional. Normative-reflexive competence makes the principles of a normative professional. Sustainable leadership is never a reality without normative professionalism. "Normative professionalism" is built on awareness of one's actions as 'value-laden' and encompasses all unified efforts towards morality in all professional obligations. Profit-organizations with the ambitious goals of sustainability should always work towards soft grounds for opening complex normative situations.

Despite the market competition of today, profit- organizations should work around the clock to streamline and harden their polices on humanistic education to avoid the culture of lost morals 
towards CSR. Basic structures for moral learning should be established financed and supported by all members of the business entity. Normative leadership is intricately connected with environmental leadership. All actions should be the output of an integrated understanding of normative professionals. Imperatively, the new generation of normative professionalism leaders should never be afraid of the worst that may come their way during their explorations towards keeping the environment clean, conducive, and suitable before, during, and in the aftermath of production operations.

\subsection{Drivers of Individual-Level Psychology}

Individuals and leaders play a critical role in explaining reality within a firm behavior. The phenomenon of bounded rationality is widespread in most companies whose market strategies are dominated by greenwashing. Managers who are perpetrators of greenwashing exhibit psychological tendencies that exacerbates the individual drivers of change. The change should be supported by optimistic decision framing and is free from the intricacies of intertemporal discounting.

Optimistic bias should be condemned and regulatory frameworks instilled to limit the over-estimation of positive events and under-estimation of the likelihood of negative implications. Unrealistic optimism, self-evaluation, and illusional control for the expansive industries of agriculture and Information Technology should be replaced through training on legitimacies on consequential predictions [59]. Decision-makers should work in the best interest of the impacts of their products and integrity towards achieving green market controls. Third-party interrogation of outcomes and evaluation should be given under regulations envisaged in the FTC (Federal Trade Commission) Act and NGO (Non-governmental organization) scrutinization.

\subsection{Upscaling the Systems of Environment Communication and Decision Information}

As the economy booms, environmental communication becomes more imperative and touching. The Research and Development departments within the structures of I.T. vendors and other industries should be reformed and shaped to suit the soaring concerns of environmentally sensitive products and by-products. In the process of changing environment communication, sustainability officers should be trained and supported to ensure there are no gaps between the consumers and the environment. Departments such as the supply chain management, product development, R\&D, marketing, and sales departments should be all part of the developments towards sustainable environmental communication and decision-making [60]. Sustainable reporting frameworks should be launched to keep all departments on a common ground of sustainable interaction with the environment.

The moment of planning and implementation of such procedural changes should be governed by a close watch on the organizational tendencies and inertia to assess the overall flexibility and rate to achieve the new balance of profitability and environmental consciousness. The whole domain of change should be guided by long-term business transformation objectives and advanced technologies to support the sustainable balance of business goals and environmental leadership [61]. All environmental performance goals should be kept in the mainstream channels of communication, with no altercation nor uncensored environmental developments. With enhanced intra-organizational communication, nothing of questionable value would be released to the market and eventually the outside world and environment. Over-estimation of likelihood events will be a thing of the past if the values of Environment Communication and Decision Information are kept true and firm from all sorts of distortions.

\subsection{Intra-Firm Communication}

Marketing is the stage of a business cycle that brings the product and service to the final consumer. From time immemorial, the art of marketing has been a massive pillar in any product's industry life. The mixed strategies of green marketing involve designing green-centered products, green promotion, green pricing, green promotion, and green consumption. The mix can be extended to other functional units in the interventions to align an organization to sustainability and sustainable leadership. They also 
encompass eco-marketing orientation as the path to success and business philosophy. Green products are fundamentally non-toxic, under packaging units that are recyclable and opens a provocative window of greening and protecting the environment [62]. The green products should be produced and subjected to reintegration strategies cognizant of the emergence and life of micro-enterprises who depend on them for their survival.

Changing the market's consumption culture requires robust strategies to revoke the former to the ecologically sensible and green destination for all new, modified, and existing products. The adjustments should be controlled and aligned according to the World Commission for Environment and Development (WCED) [63]. In a significant way, all strategies, and activities are of online and suitable development. For instance, I.T. products and electronic devices are taking over the world of today. As of today, e-waste and hardware waste management have been deteriorated a question. The Figure 2 indicates the summary diagram which shows the most imperative interventions and solutions towards sustainable leadership and environmental sensitivity.

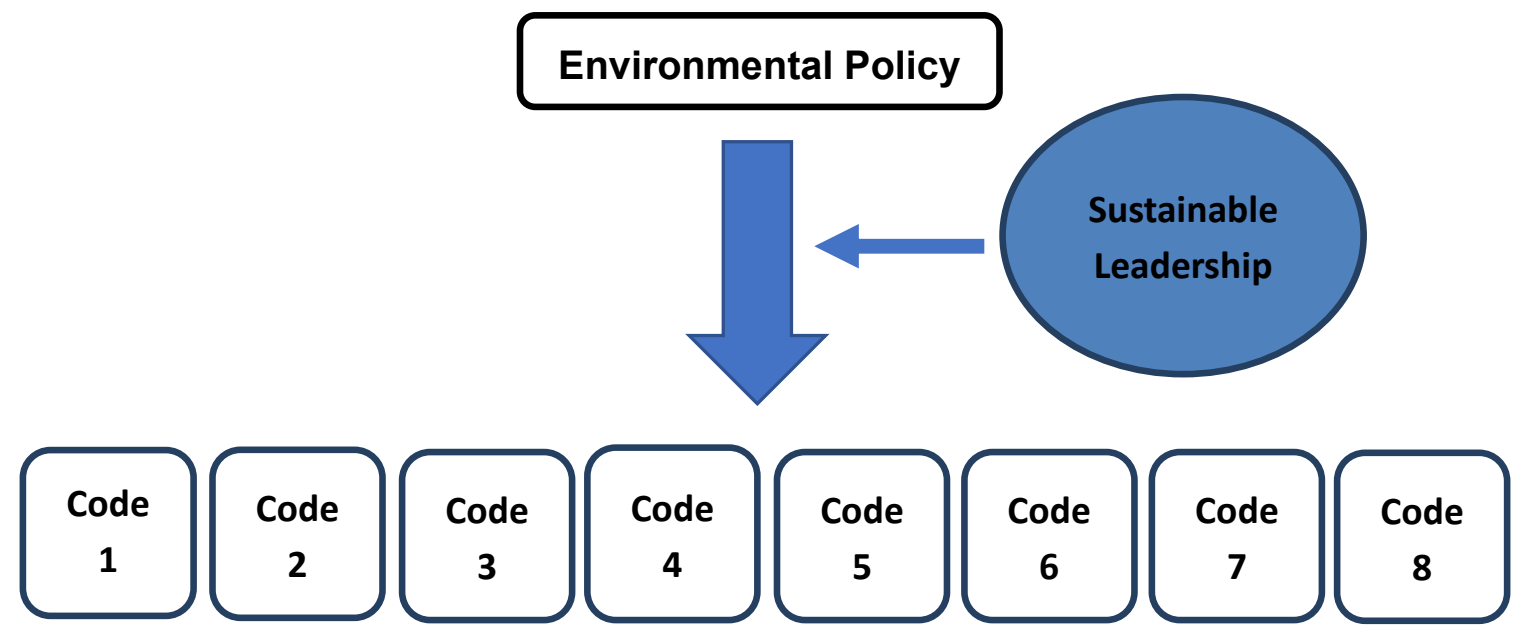

Figure 2. The summary Diagram of Solutions through aspects of sustainable leadership. Code 1—CSR; Code 2-Waste Management; Code 3-Fighting the Vicious Culture of Greenwashing; Code 4-Intra-firm Communication; Code 5-Ethical Climate and Incentive Structure; Code 6-Supporting Leadership in making of Normative Professionals; Code 7-Drivers of Individual-Level Psychology; Code 8-Keeping Values of Environment Communication and Decision.

\subsection{Originality/Value}

Given that the challenges and opportunities of environmental sustainability are rooted in leadership as a change agent, classifying, blending, and integrating ideal leadership attributes and styles is a valuable and inimitable input of this research. The research thus motivates a consideration for leadership as a critical element in augmenting environmental sustainability within a competitive environment. The value of this research is that it identifies command as a crucial agent through servant leadership and authentic leadership by attaining competitive corporate greening to achieve organizational competitiveness and realize environmental stewardship.

Substantial studies that exist describe the urgent need and the intractable nature of the issues facing organizations today, such as environmental sustainability and, to a specific degree, how corporates can become stewards of change. This research presents a framework of solutions to develop more environmentally sustainable decisions with leaders as the mediating mechanism towards this objective. As a result, the study reveals solutions that can create sustainability companies due to deliberate leadership actions that connect the organization to society and the planet. The current research also mostly focuses on profit and how it relates to environmental sustainability and the role of leaders in that endeavor. However, this research is integral because it develops environmental sustainability solutions with the leader's leadership style as imperative for attaining deliberate goals. 


\section{Conclusions and Recommendation}

\subsection{Conclusions}

Environmental issues are here to stay, and the future depends on the preparedness of business ventures to adopt the ultimate approaches of suitable leadership. The term sustainable development has been defined and described vividly. This research also discusses the challenges of environmental issues. To ensure that long term production, marketing, and innovation are environmentally sensitive, the solution towards sustainability in the environment and leadership is imperative. Some of the critical solutions offered include: fighting the vicious culture of greenwashing in I.T. products and E-waste, Corporate Social Responsibility (CSR), ultra-regulatory environment, intra-firm communication, green marketing, ethical climate, and incentive structure. In the above approaches, sustainable leadership becomes a broader vehicle of sustainable environmental protection. The highlighted solutions give a medium and long-term policy projection to foster livelihood models, alternate economic and product development with stringent adherence to growth prospects, and environmental protection. The key to the above greening approaches is credibility with no focus on the overestimation claims that surround the marketing industry. Environmental leadership is the heart of a good and green economy. The dilemma between profitability and the impact of business on the environment is creating an endless discussion all over the world. The time to use our business for the external and environmental gains is long overdue. The intriguing impact of environmental degradation is a very deadly mess for any business enterprise.

This research aimed to explore existing literature for solutions that leaders can use to attain sustainable leadership. The current researchers accomplished this aim by using content analysis to investigate solutions elaborated as essential working solutions to achieve sustainable leadership. The current researchers found and coded key themes, found eleven solutions from existing literature that would help leaders create ecologically sensitive organizations. This research aimed to examine the role of leadership in enhancing solutions for advanced environmental sustainability practice. Globalization, especially, is a challenge that presents various sustainability issues for the modern business, thus requiring servant leaders and transformative leaders [64]. The current researchers used a qualitative methodology and thus used methods that align with these methods. Also, the current researchers used content analysis to analyze the peer-reviewed material collected from the existing literature. Content analysis was the most preferred technique because it was easier to find measurements for validity through this process. The measure used to validate the study included the entire body of literature listing solutions for organizations on environmental sustainability.

The first solution is Corporate Social Responsibility (CSR) because of how it benefits the community. The research found that environmental sustainability is an essential aspect of CSR as it seeks to make a positive difference in society through a set of actions. We also noted that environmental sustainability is an aspect that requires the integration of technology to reduce waste, for instance, by automating production processes. Technology can solve various ecological issues if leaders can integrate the right focus on not only technology advancement but technological-efficient solutions such as smart-grids, fuel cells, and lithium-air batteries, and also hydrogen energy collectors. Another solution that we found was to mitigate greenwashing, and the false impression about a firm's product leaders should adopt better cultures for ethical climate sensitivity. The current researchers also found ultra-regulatory environments as a solution for fostering sustainable environmental leadership. The solution supports for fines to nourish firms that use misleading adverts, especially greenwashing. Organizational sustainability drivers are another solution that seeks to adopt changes to enhance sustainability leadership and to limit greenwashing activities while still asserting on intra-firm communication.

Intra-firm communication is a solution to environmental leadership sensitivity, especially against greenwashing. Leaders who inspire better environments offer a forum for sharing information and reducing inadvertent greenwashing. The current researchers found that establishing an ethical climate and incentive structure would be useful for leaders in modern firms. Accurately, organizations should 
implement moral values and practices that would create appropriate corporate cultures. We also found that firms use reward structures (incentives) that are vital for attaining fiscal business objectives and CSR programs such as environmental sustainability leadership. We additionally found that research signifies the importance of normative professionalism, where leaders and all individuals in the firm understand the impact of their decisions. As well, leaders should be the drivers of individual-level psychology, meaning that leaders ought to lessen biases that would negatively impact green market controls. Research has also noted that organizations need to invest in systems that would augment environmental communication, which is also of imperative significance when attempting to encourage intra-firm discussion.

However, all these solutions are possible when leaders with appropriate skills are at the helm to inspire environmental leadership. Servant leaders are revolutionary as they take the obligation of reversing conventional ways of thinking into new, more sustainable models. The servant-leader thus changes the dynamic of hierarchy by being at the bottom to serve employees and, in that way, creating an empowering and uplifting mindset for people. Through servant leadership, the leader enhances a collaborative workplace instead of commanding, fusing with changes a leader needs to implement. As such, servant leadership is crucial in all aspects of the firm because environmental leadership becomes a lifestyle to the people the leader serves. The results of servant leadership are augmented performance because, unlike traditional leaders, a servant leader is at the center of change. After all, servant leaders augment and align employees' idealized vision with the firm's vision and core values. Due to servant leadership, the workforce will be more willing to assert creative and innovative methods that encourage environmental sustainability.

Authentic leaders are also vital role in enhancing environmental sustainability. The workforce will be more willing to innovate according if a leader is a sustainability champion. Indeed, authentic leadership is crucial because leaders lead by example and, as a result, builds firms that have empowering habits. Honest relationships are essential in the environmental direction because followers value leaders who value their input. The world requires leaders who encompass the traits of an authentic leader because they have a great sense of purpose and the direction, they need the firm to be. Authentic leadership is hence critical in this discussion because it promotes sustainable companies with leaders and the employees at the center of change. Therefore, leaders need to embrace servant and authentic leadership styles because they can augment a sense of change within employees without acting as commanders but as servants and trustworthy persons within the organization. Without such leadership integrating change, it would be challenging to implement the solutions framework integrated into this discourse. Noting that traditional leadership models do not offer solutions for findings solutions to new problems facing workplaces, organizations must apply servant and authentic leadership that can deliberately tackle environmental sustainability with everyone as part of a team.

\subsection{Limitations}

This research was inductive mainly and, thus, qualitative. The problem with qualitative studies is that they rely on the researcher, and hence validity and reliability of the research is somewhat low. Therefore, further research ought to incorporate a method that would augment the efficacy of the result found by combining a positivist approach, which would be useful in triangulating the research results. As noted in this study, content analysis is open to abstraction level and interpretation degree issues. Thus, a need to include primary research could inform on the content analysis conducted. This research review would also benefit from research that incorporates a systematic review method because it will help delineate the solutions suggested in order of importance.

\subsection{Implication for Practice}

The findings from this research imply that modern organizations require charismatic leaders who can inspire change through motivation by using servant leadership. The results also indicate a massive gap between leadership courses and the integration of environmental sustainability. Business 
schools, in particular, need to integrate training and other developmental approaches that can help teach leaders to be environmentally-centric, while still looking into the other success metrics of the firm. Research suggests that sustainability will feature now and, in the years, to come and will be a crucial aspect of business performance [12]. As such, the solutions illustrated in this research would be vital for modern leaders who must meet both corporate and environmental objectives. Therefore, leaders must be servants and authentic leaders to augment a sense of change.

\subsection{Recommendation}

Based on the above research study, it can be proposed that future analysis could explore values and frames that can solve contemporary sustainability and leadership issues. The findings demonstrate the intricacies that sustainable leaders face in the blending paradigm's interests, involvements, and considerations. Future studies should focus on integrating personal responsibility, business considerations for a new phase of production systems, and practices within organizations. Corporate greening should be governed by a new and modified protocol framework to control the implications of new and modified products to the broader environment.

Future research could be conducted to examine the influence and role of cultural diversity and differences on the strengths and values it brings to environmental leadership and the development of consciousness culture. A heightened focus on SMEs would illuminate more light on the diverse sphere of ethics and environmental leadership on visionary attributes that may differ from the background post-convenient steps. The center could also be extended to mention the contemporary role and influence of technology in CSR and war against greenwashing menace. A future study could also focus on family businesses and their role in fighting environmental issues. The war against adversities caused by weak sustainability in leadership and environmental impacts is far from over. The 21st century is just a new and perplexing space for business sustainability and transition to ecological consciousness. Business is no longer a matter of profit-making and financial muscles but a frontier for changing how we interact with and exploit the natural world. Post-conventional technologies should come to the discussion if the business planet is to make any strides towards sustainability and environmental protection.

Intra-firm communication is a unique tool for realizing business approaches and production cycles dominated by sustainable leadership and sensitivity to the environment. Accounting is a powerful behavioral practice that can be adopted in policies of sustainable administration. Future research should, hence, embark on integrated accounting systems to foster and enhance interdepartmental corporation and integrity. The role of integrity in the establishments of accounting systems should also be analyzed and systemically improved and protected. Besides, scrutiny should be meant on the connectivity between accounting and organizational learning systems. The world is changing, and the environmental factors of doing are equally changing. Studies on effective learning systems should be done to ensure that future leadership understands the bond between sustainability and the environment. The soaring role of technology should not be ignored in all intra-communication systems. More profound studies should be done to keep a secure technology role in the operations and protocols of intra-communication. The considerations of technology should be kept at their highest levels of business intelligence. If intelligence is not a critical insight, the advanced technology may threaten and corrupt the systems set up to ensure a mutually beneficial relationship between organizational units.

There are novel approaches to CSR management today, since CSR plays a key imperative role in environmental sustainability. Management control systems have been vital in this endeavor since CSR is a mediator for improving society as the firms attain other business objectives. Prior study to examine systems used for CSR management found that firms use management control systems to "satisfy salient stakeholder demands, manage legitimacy and reputation issues, and meet top management expectations and enhance their commitment." [65]. Also, another prior study asserted that organizations use management control systems to enhance CSR and business objectives. Included in the management control systems are environmental management systems that play a critical role 
in the coordination, monitoring and management of data related to environmental strategies [66]. EMS (Environment Management System) encompasses various issues that are essential for advancing sustainability sensitivity among leaders and employees. For instance, an EMS includes budges, performance metrics and risk management processes a firm used in a certain period. These metrics are crucial because they can help a business track environmental sustainability progress and the business strategy. Therefore, all firms need to adopt management control systems not only for elements that concern business strategy but also for environmental sustainability progress. Since CSR is directly associated with environmental sustainability, the EMS should be adopted on every "greening" platform and strategic digital literacy protocols. The future looks very bright with specialized machine management accounting. More resources should be pumped into the management systems designed to support and enhance environmental positivity.

The current research will benefit business research and practice because the leadership perspectives about augmenting environmental stewardship can align consumer satisfaction with the business goals. In particular, further research will find how businesses can fuse CSR by eliminating green washing and encouraging ultra-regulatory environment, intra-firm communication, and organizational sustainability. Drivers and ethics augment the growth of sustainable leadership within the business. This research would also benefit from understanding how servant and authentic leadership would be critical in expanding a firm's competitiveness in light of environmental sustainability. The objective would be to assess the value of leadership using a resourced based view theory (RBV) to determine how companies can attain both the profit and environmental stewardship within the firm context. Indeed, most studies only cover the benefits to profit for companies concerning ecological sustainability. Businesses need to evaluate the RBV view is imperative from the direction of authentic and servant leadership to attain corporate sustainability. The benefit of this view is that it will assess the viability and environmental leadership through servant and authentic leadership in changing consumer behavior towards a firm's advantage. Regardless, this research demonstrates that leaders in the business field can help augment environmental stewardship through the solutions suggested.

Author Contributions: Both E.-J.W. and E.K. contributed conceptualization, designing research framework, and writing original draft. Specifically, E.-J.W. investigated to find out all resources and applied them to the research framework. All authors have read and agreed to the published version of the manuscript.

Funding: This research received no external funding.

Conflicts of Interest: The authors declare no conflict of interest.

\section{References}

1. Van Rheede, A.; Blomme, R.J. Sustainable practices in hospitality: A research framework. Adv. Hosp. Leis. 2012, 8, 257-271. [CrossRef]

2. Dahlgaard-Park, S.M.; Dahlgaard, J.J.; Canning, J.; Found, P.A. The effect of resistance in organizational change programmes: A study of a lean transformation. Int. J. Qual. Serv. Sci. 2015, 7, 274-295.

3. Slimane, M. Role and relationship between leadership and sustainable development to release social, human, and cultural dimension. Procedia-Soc. Behav. Sci. 2012, 41, 92-99. [CrossRef]

4. Casey, D.; Sieber, S. Employees, sustainability and motivation: Increasing employee engagement by addressing sustainability and corporate social responsibility. Res. Hosp. Manag. 2016, 6, 69-76. [CrossRef]

5. Cantor, D.E.; Morrow, P.C.; Montabon, F. Engagement in environmental behaviors among supply chain management employees: An organizational support theoretical perspective. J. Supply Chain Manag. 2012, 48, 33-51. [CrossRef]

6. Brodhag, C.; Talière, S. Sustainable development strategies: Tools for policy coherence. Nat. Resour. Forum. 2006, 30, 136-145. [CrossRef]

7. Basiago, A.D. Economic, social, and environmental sustainability in development theory and urban planning practice. Environmentalist 1998, 19, 145-161. [CrossRef]

8. Milne, M.; Gray, R. W(h)ither Ecology? The triple bottom line, the global reporting initiative, and corporate sustainability reporting. J. Bus. Ethics 2012, 118, 13-29. [CrossRef] 
9. Ben-Eli, M. Sustainability: Definition and Five Core Principles-A New Framework. NYinfo@sustainabilitylabs.org. Available online: http://www.sustainabilitylabs (accessed on 20 June 2020).

10. Hák, T.; Janoušková, S.; Moldan, B. Sustainable Development Goals: A need for relevant indicators. Ecol. Indic. 2016, 60, 565-573. [CrossRef]

11. World Bank. Atlas of Sustainable Development Goals. World Development Indicators. 2017. Available online: https://documents.worldbank.org/en/publication/documentsreports/documentdetail/21757149388355567 7/atlas-of-sustainable-development-goals-2017-from-world-development-indicators (accessed on 8 June 2020).

12. McCann, J.T.; Holt, R.A. Defining sustainable leadership. Int. J. Sustain. Strat. Manag. 2010, 2, 204. [CrossRef]

13. Swarnapali, N. Corporate Sustainability: A Literature review. J. Account. Res. Educ. 2017, 1, 1-16.

14. Kumar, S. Literature review on leadership, leadership theories. Style and leadership development. Int. J. Res. Bus. Manag. 2018, 6, 13-24.

15. Hargreaves, A.; Fink, D. Sustainable Leadership; John Wiley \& Sons: San Francisco, CA, USA, 2012.

16. Malik, S.Z.; Saleem, M.; Naeem, R. Effect of leadership styles on organizational citizenship behaviour in employees of telecom sector in Pakistan. Pak. Econ. Soc. Rev. 2016, 54, 385-406.

17. Spears, L.C. Character and servant leadership: Ten characteristics of effective, caring leaders. J. Virtues Leadersh. 2010, 1, 25-30.

18. Yukl, G.A. Leadership in Organizations; Pearson: Boston, MA, USA, 2013.

19. Duru, C.U. Environmental Degradation: Key Challenge to Sustainable Economic Development in the Niger Delta. Walden Dissertations and Doctoral Studies. Available online: http://scholarworks.waldenu.edu/cgi/v iewcontent.cgi? article $=1113 \&$ context=dissertations (accessed on 17 June 2020).

20. Wanamaker, C. The Environmental, Economic, and Social Components of Sustainability. 2018. Available online: https://soapboxie.com/social-issues/The-Environmental-Economic-and-Social-Components-of-Su stainability (accessed on 15 June 2020).

21. Mensah, J.; Casadevall, S.R. Sustainable development: Meaning, history, principles, pillars, and implications for human action: Literature review. Cogent Soc. Sci. 2019, 5, 1653531. [CrossRef]

22. Leuenberger, D. Symposium—Sustainability and public administration. Adm. Theory Prax. 2017, 29, 370-374.

23. Basu, S.; Roy, M.; Pal, P. Corporate greening in a large developing economy: Pollution prevention strategies. Environ. Dev. Sustain. 2018, 21, 1603-1633. [CrossRef]

24. Bathmanathan, V.; Hironaka, C. Sustainability and business: What is green corporate image? In Proceedings of the International Conference on Advances in Renewable Energy and Technologies, Putrajaya, Malaysia, 23-25 February 2016; p. 012049.

25. Olson, E.G. Creating an enterprise level “green” strategy. J. Bus. Strat. 2008, 29, 22-30. [CrossRef]

26. Bruyere, B.L. Giving direction and clarity to conservation leadership. Conserv. Lett. 2015, 8, 378-382. [CrossRef]

27. Khachaturyan, N. Environmental Leadership: Emphasizing the Role of Environmental Leaders. Journal of Armenian Environmental Network. Available online: https://www.armenia-environment.org/blog/2017/11/1 0/environmental-leadership-emphasizing-the-role-of-environmental-leaders (accessed on 29 May 2020).

28. Al-Ababneh, M.M. Linking ontology, epistemology and research methodology. Sci. Philos. 2020, 8, 75-91.

29. Chowdhury, M.F. Interpretivism in aiding our understanding of the contemporary social world. Open J. Philos. 2014, 4, 432-438. [CrossRef]

30. Gaus, N. Selecting research approaches and research designs: A reflective essay. Qual. Res. J. 2017, 17, 99-112. [CrossRef]

31. Creswell, J.W.; Creswell, J.D. Research Design: Qualitative, Quantitative, and Mixed Methods Approaches; Sage Publications: Newbury park, CA, USA, 2017.

32. Borowska-Beszta, B. Ethnography of education and re-education: A triad of threads and traps. Int. Res. J. Qual. Educ. 2019, 6, 20-29.

33. Ward, J.H. Managing Data: Content Analysis Methodology. Unpublished Manuscript, University of North Carolina at Chapel Hill. Creative Commons License: Attribution-NoDerivatives. 2012, Volume 4, pp. 2-31. Available online: http://www.impactzone.co/wp-content/uploads/2016/05/final-ca-lr-jhw-updated-compres sed.pdf (accessed on 20 June 2020).

34. Neuendorf, K.A. The Content Analysis Guidebook; SAGE Publications: Thousand Oaks, CA, USA, 2002.

35. Hammarberg, K.; Kirkman, M.; De Lacey, S. Qualitative research methods: When to use them and how to judge them. Hum. Reprod. 2016, 31, 498-501. [CrossRef] [PubMed] 
36. Kitto, S.C.; Chesters, J.; Grbich, C. Quality in qualitative research. Med. J. Aust. 2008, 188, 243-246. [CrossRef] [PubMed]

37. Neuendorf, K.A.; Gore, T.D.; Dalessandro, A.; Janstova, P.; Snyder-Suhy, S. Shaken and stirred: A content analysis of women's portrayals in James Bond films. Sex Roles 2009, 62, 747-761. [CrossRef]

38. Graneheim, U.; Lundman, B. Qualitative content analysis in nursing research: Concepts, procedures and measures to achieve trustworthiness. Nurse Educ. Today 2004, 24, 105-112. [CrossRef]

39. Jain, V.; Roy, S.; Daswani, A.; Sudha, M. How celebrities are used in indian television commercials. Vikalpa 2010, 35, 45-52. [CrossRef]

40. Naccarato, J.L.; Neuendorf, K.A. Content analysis as a predictive methodology: Recall, readership, and evaluations of business-to-business print advertising. J. Advert. Res. 1998, 38, 19-29.

41. Liberati, A.; Altman, D.G.; Tetzlaff, J.; Mulrow, C.; Gøtzsche, P.C.; Ioannidis, J.P.A.; Clarke, M.; Devereaux, P.J.; Kleijnen, J.; Moher, D. The PRISMA Statement for reporting systematic reviews and meta-analyses of studies that evaluate health care interventions: Explanation and elaboration. PLoS Med. 2009, 6, e1000100. [CrossRef]

42. Tam, W.W.S.; Tang, A.; Woo, B.F.Y.; Goh, Y.S. Perception of the preferred reporting items for Systematic Reviews and Meta-Analyses (PRISMA) statement of authors publishing reviews in nursing journals: A cross-sectional online survey. BMJ Open 2019, 9, e026271. [CrossRef]

43. Rahman, $\mathrm{S}$. The advantages and disadvantages of using qualitative and quantitative approaches and methods in language "testing and assessment" research: A literature review. J. Educ. Learn. 2016, 6, 102. [CrossRef]

44. Queirós, A.; Faria, D.; Almeida, F. Strengths and limitations of qualitative and quantitative research methods. Eur. J. Educ. Stud. 2017, 3, 369-387.

45. Graneheim, U.H.; Lindgren, B.-M.; Lundman, B. Methodological challenges in qualitative content analysis: A discussion paper. Nurse Educ. Today 2017, 56, 29-34. [CrossRef]

46. Wilson, F.; Post, J.E. Business models for people, planet (\& profits): Exploring the phenomena of social business, a market-based approach to social value creation. Small Bus. Econ. 2011, 40, 715-737. [CrossRef]

47. Smith, T. Two sides of the coin: Shareholders engaging companies on sustainability Issues/Companies promoting CSR leadership as good business. J. Investig. 2011, 20, 103-107. [CrossRef]

48. Abhishek, T.; Roy, T.; Singh, R. Corporate Social Responsibility (CSR) and environmental protectionThe way forward. Int. J. Res. Soc. Sci. 2014, 4, 230-248.

49. Hohnen, P. Corporate Social Responsibility: An Implementation Guide for Business; International Institute for Sustainable Development: Winnipeg, MB, Canada, 2007. Available online: https://www.iisd.org/sites/default /files/publications/csr_guide.pdf (accessed on 11 June 2020).

50. Jiao, Y.; Xie, W. How Does CSR Influence a Firm's Profitability? A Case Study of Sandvik. 2013. Available online: https://www.diva-portal.org/smash/record.jsf?pid=diva2\%3A630572\&dswid=-2066 (accessed on 15 June 2020).

51. Aydalot, P.; Keeble, D. High Technology Industry and Innovative Environments; The European Experience; Routledge: London, UK, 2018; Volume 3.

52. Chan, A. Environmental issues and the information technology industry. J. Bus. Adm. Soc. Sci. 2011, 6-158.

53. Delmas, M.A.; Burbano, V.C. The drivers of greenwashing. Calif. Manag. Rev. 2011, 54, 64-87. [CrossRef]

54. Ramus, C.A.; Montiel, I. When are corporate environmental policies a form of greenwashing? Bus. Soc. 2005, 44, 377-414. [CrossRef]

55. Liu, N.; Tang, S.-Y.; Zhan, X.; Lo, C.W.-H. Political commitment, policy ambiguity, and corporate environmental practices. Policy Stud. J. 2015, 46, 190-214. [CrossRef]

56. Vos, J. Actions speak louder than words: Greenwashing in Corporate America. Notre Dame J. Law Ethics Public Policy 2009, 23, 673-697.

57. Keskes, I. Relationship between leadership styles and dimensions of employee organizational commitment: A critical review and discussion of future directions. Intang. Cap. 2014, 10, 26-51. [CrossRef]

58. Derchi, G.-B.; Zoni, L.; Dossi, A. Corporate social responsibility performance, incentives, and learning effects. J. Bus. Ethics 2020, 1-25. [CrossRef]

59. Fiaz, M.; Su, Q.; Saqib, A. Leadership styles and employees' motivation: Perspective from an emerging economy. J. Dev. Areas 2017, 51, 143-156. [CrossRef]

60. Gholami, R.; University of Illinois Springfield; Watson, R.; Hasan, H.; Molla, A. Information systems solutions for environmental sustainability: How can we do more? J. Assoc. Inf. Syst. 2016, 17, 521-536. [CrossRef] 
61. Rogers, K.S. Exploring our ecological selves within learning organizations. Learn. Organ. 2012, $19,28-37$. [CrossRef]

62. Singh, S.K.; Del Giudice, M.; Chierici, R.; Graziano, D. Green innovation and environmental performance: The role of green transformational leadership and green human resource management. Technol. Forecast. Soc. Change 2020, 150, 119762. [CrossRef]

63. Yazdanifard, R.; Voon Teo, Y. Green Marketing Strategies, Sustainable Development, Benefits and Hallenges/Constraints. Future of R\&D Outsourcing in Global Enterprise. 2014. Available online: https://w ww.academia.edu/8073438/Green_marketing_strategies_sustainable_development_benefits_and_challenge S_and_constraints (accessed on 21 June 2020).

64. Middlebrooks, A.; Miltenberger, L.; Tweedy, J.; Newman, G.; Follman, J. Developing a sustainability ethic in leaders. J. Leadersh. Stud. 2009, 3, 31-43. [CrossRef]

65. Laguir, L.; Laguir, I.; Tchemeni, E. Implementing CSR activities through management control systems. Account. Audit. Account. J. 2019, 32, 531-555. [CrossRef]

66. Arjaliès, D.-L.; Mundy, J. The use of management control systems to manage CSR strategy: A levers of control perspective. Manag. Account. Res. 2013, 24, 284-300. [CrossRef]

(C) 2020 by the authors. Licensee MDPI, Basel, Switzerland. This article is an open access article distributed under the terms and conditions of the Creative Commons Attribution (CC BY) license (http://creativecommons.org/licenses/by/4.0/). 